\title{
VIDEO PROFILE CONTACT CENTER 121 PADA PT. KAI (PERSERO)
}

\author{
Deden Rustiana ${ }^{1}$ \\ Ferry Sudarto ${ }^{2}$ \\ Al Marwan ${ }^{3}$ \\ Dosen STMIK Raharja Tangerang ${ }^{1,2}$, Mahasiswa STMIK Raharja Tangerang ${ }^{3}$ \\ Jl. Jenderal Sudirman No.40 Modernland Cikokol, Tangerang ${ }^{1,2,3}$ \\ e-mail: $\underline{\text { deden.rustiana@ raharja.info }}{ }^{1}, \underline{\text { ferry.sudarto@ raharja.info }}{ }^{2}, \underline{\text { marwan @ raharja.info }}^{3}$
}

\begin{abstract}
ABSTRAK
Saat ini keterbukaan akses informasi memungkinkan informasi dapat dengan mudah diperoleh kapanpun dan dimanapun. Informasi menjadi hal penting karena dengan informasi orang akan mendapat semua yang diinginkan. Penyebaran informasi tersebar melalui media cetak atupun media elektronik berbentuk multimedia, dari media itulah masyarakat dapat memperoleh informasi. PT Kereta Api Indonesia (Persero) adalah salah satu instansi pemerintah di bidang transportasi perkeretaapian yang masih menggunakan media lisan dan tulisan, dan websiteter utama pada bagian Contact Center 121, namun media tersebut kurang efektif untuk menginformasikan dan memperkenalkan PT Kereta Api Indonesia (Persero) Contact Center 121 membutuhkan media video informasiuntuk menunjang berbagai kegiatan seperti menginformasikan kepada masyarakat luas khususnya untuk usaha menegah yang berniat untuk menunjukan usaha menengah atau home industry. Pada konsep tersebut terdapat tahapan preproduction, production dan postproduction. Agar menghasilkan rancangan media berbasis video informasi yang baik dan berkualitas digunakan aplikasi penunjang adobe photoshop CS3, Adobe Premier CS3 dan afterb effek CS3.
\end{abstract}

Kata kunci: media, video, informasi.

\begin{abstract}
At this time, access to information allows information to be easily obtained whenever and wherever. Information becomes important, because with information people will get everything they want. Information dissemination is spread through print media or electronic media in the form of multimedia, from which the media can obtain information. PT KeretaApi Indonesia (Persero) is one of the government agencies in the field of railway transportation that still uses oral and written media, and the website includes 121 Contact Center sections, but the media is less effective in informing and introducing PT KeretaApi Indonesia (Persero) Contact Center 121 requires information media to support various activities such as informing to the wider community especially for medium-sized businesses that intend to show medium-sized businesses or home industries. In the concept there are stages of preproduction, production and postproduction. In order to produce a good and quality information-based video media design used adobe photoshop CS3, Adobe Premier CS3 and afterb CS3 support applications.
\end{abstract}

Keyword: media, video, information. 


\section{PENDAHULUAN}

Badan Usaha Milik Negara Indonesia yang menyelenggarakan jasa angkutan kereta api. Layanan PT. KAI (Persero) meliputi angkutan penumpang dan barang. Saat ini, PT. KAI (Persero) memiliki tujuh anak perusahaan yakni PT Reska Multi Usaha. Nama DKARI kemudian diubah menjadi Perusahaan Negara Kereta Api (PNKA). Nama itu diubah lagi menjadi Perusahaan Jawatan Kereta Api (PJKA).

\section{RUMUSAN MASALAH}

Dengan video informasi dapat digunakan sehingga masyarakat mengenal hingga lebih mudah yang berisikan informasi yang berupa penjelasan detail isi video yang kualitasnya lengkap setiap yang melihatnya. Mengenai video informasi memiliki visual, gambar, dan suara dikemas kedalam video profile, dan video ini ditampilkan dalam durasi yang tidak terlalu panjang namun jelas, agar lebih efektif dan tepat sasaran video ini di implementasikan melalui video profile PT.KAI (PERSERO).

\section{LANDASAN TEORI}

Pengertian Projek

usaha sementara,temporer, yang memiliki sasaran khusus dengan waktu pelaksanaan yang tegas.

\section{Pengertian Informasi}

sesuatu data yang sudah diolah atau diproses sehingga menjadi suatu bentuk yang memiliki arti bagi penerima informasi yang memiliki nilai yang bermanfaat.

\section{Pengertian Media}

Segala sesuatu yang dapat digunakan untuk menyalurkan pesan dari pengirim ke penerima sehinga dapat merangsang pikiran, perasaan, perhatian dan minat serta perhatian siswa sedemikian rupa sehingga proses belajar terjadi.

\section{Pengertian Video}

Teknologi untuk menangkap, merekam, memproses, mentransmisikandan menata ulang gambar bergerak. Biasanya menggunakan film seluloid, sinyal elektronik, atau media digital.

\section{Pengertian Audio}

Salah satu elemen penting yang ikut berperan dalam membangun sebuah sistem komunikasi dalam bentuk suara, yaitu suatu sinyal elektrik yang akan membawa unsur bunyi didalamnya.

\section{Perencanaan Multimedia}

Kombinasi dari teks, grafis, seni,suara, dan video yang dikirimkan oleh komputer/peralatan elektronik lainnya

\section{Tujuan Multimedia}

kombinasi dari beragam bentuk teks, audio, video, gambar dan animasi untuk memberikan informasi atau hiburan kepada pengguna. 


\section{Tahapan Produksi Audio Visual}

\section{Pra Produksi}

"Praproduksi (perencanaan) kegiatan dengan liputan (shooting). kegiatan praproduksi antara lain penuangan ide (gagasan) outline, scenario/pembuatan format/ script/ treatment, storyboard, Survey lokasi, production meeting, technical meeting, dekor, dan lain-lain.”

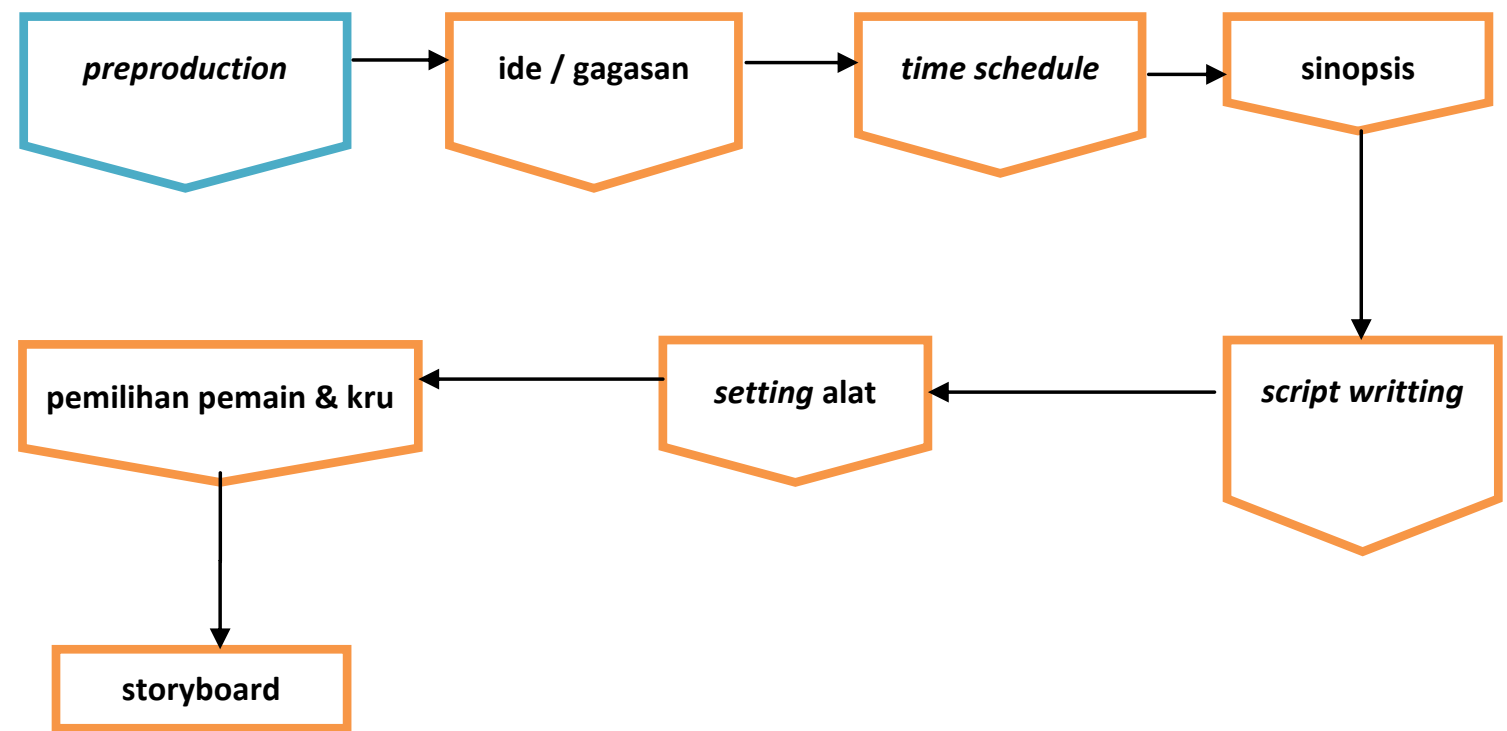

Gambar 1. Tahapan Pra Produksi

\section{Produksi}

"memproduksi program doku-drama agak mirip dengan memproduksi program dokumenter. Namun dalam doku-drama adegan yang terjadi di masa lalu bisa direkayasa." 


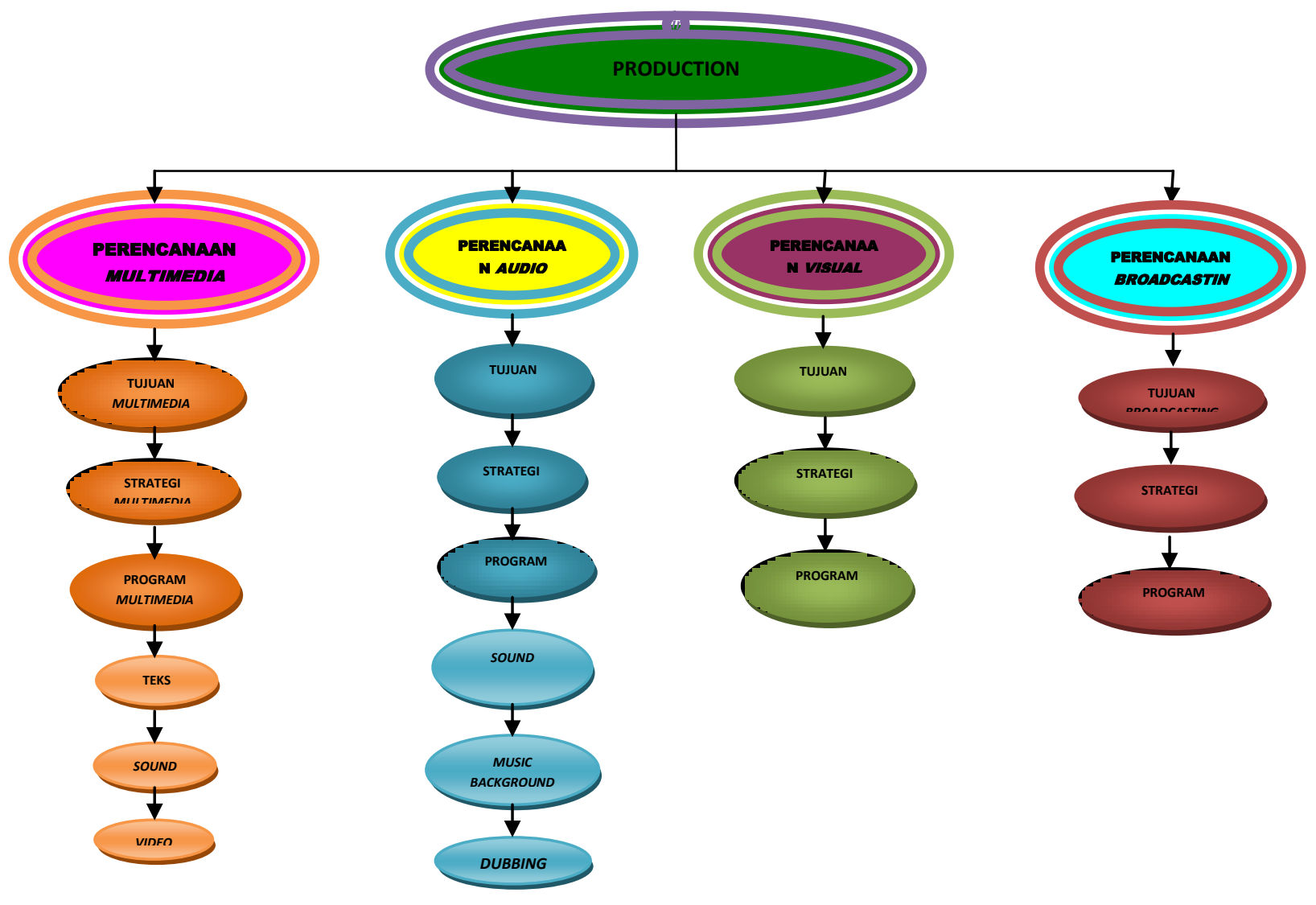

Gambar 2. Tahapan Produksi

\section{Post Produksi}

"Pasca produksi (penyuntingan) peliputan/shooting/taping sehingga materi selesai disiarkan atau diputar kembali.

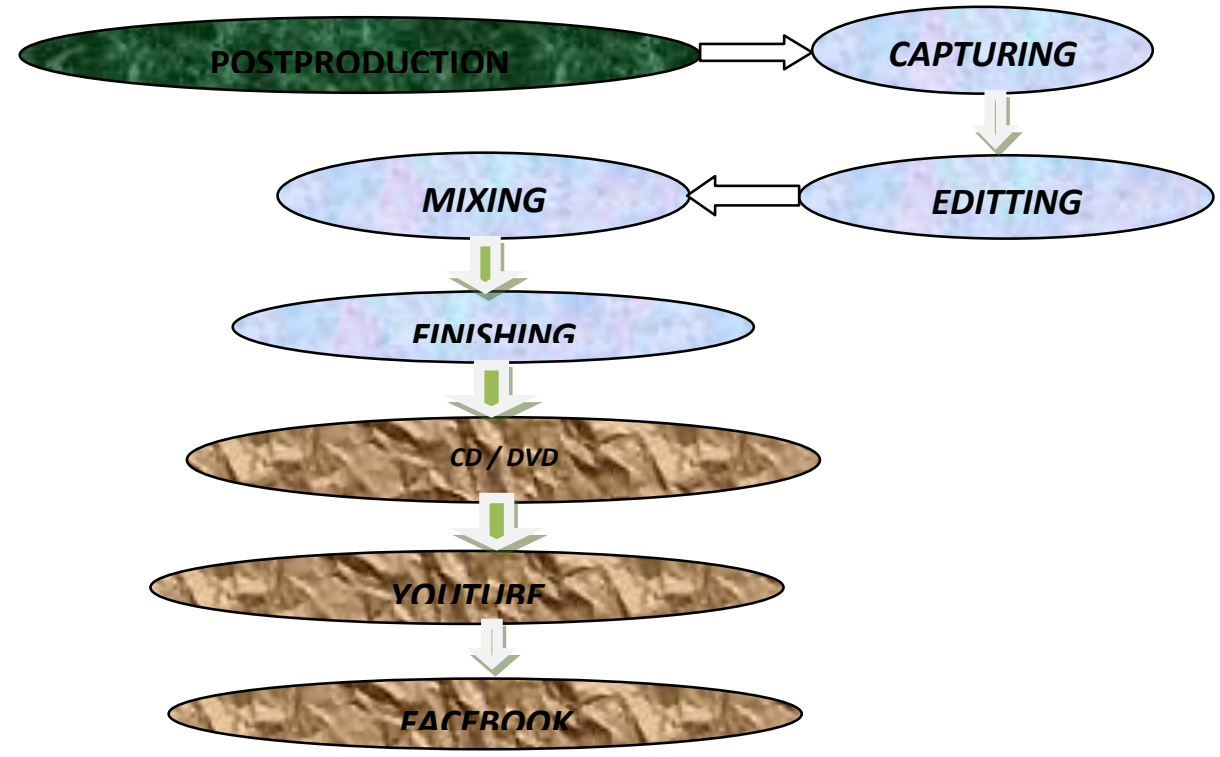

Gambar 3. Pasca Produksi 


\section{Storyboard}

Scene 1

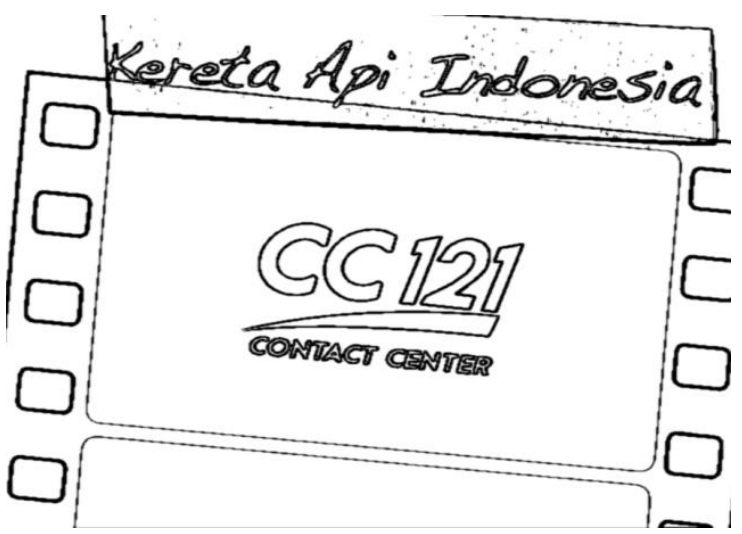

Bumper Opening Contact Center 121

Gambar 4. Bumper Opening Contact Center 121

\section{Scene 2}

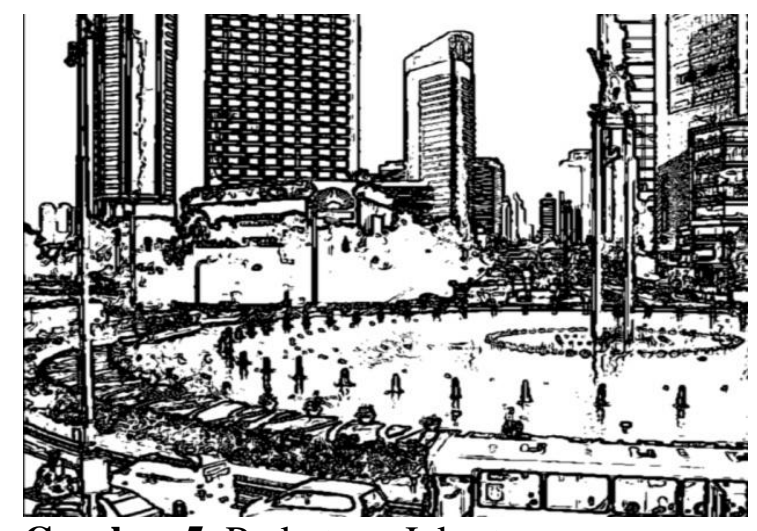

EXT/Perkotaan Jakarta (Full Shoot)

Gambar 5. Perkotaan Jakarta

Scene 3

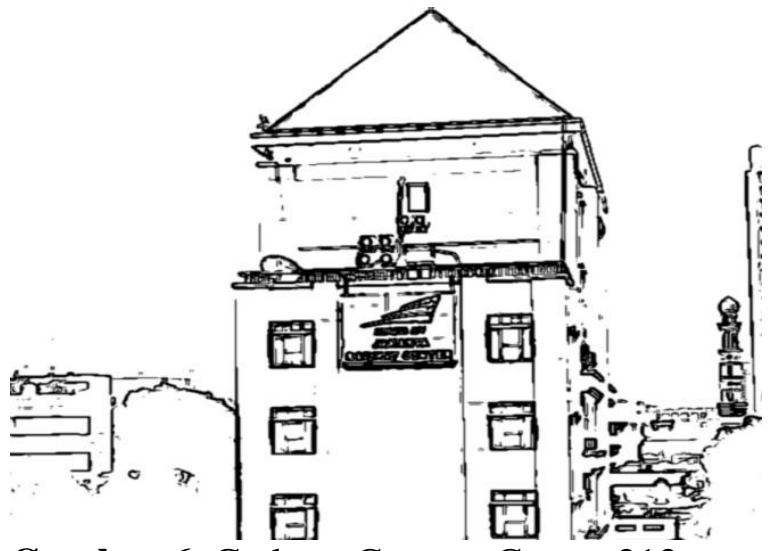

EXT / Gedung Contact Center 212 (Full Shoot)

Gambar 6. Gedung Contact Center 212 


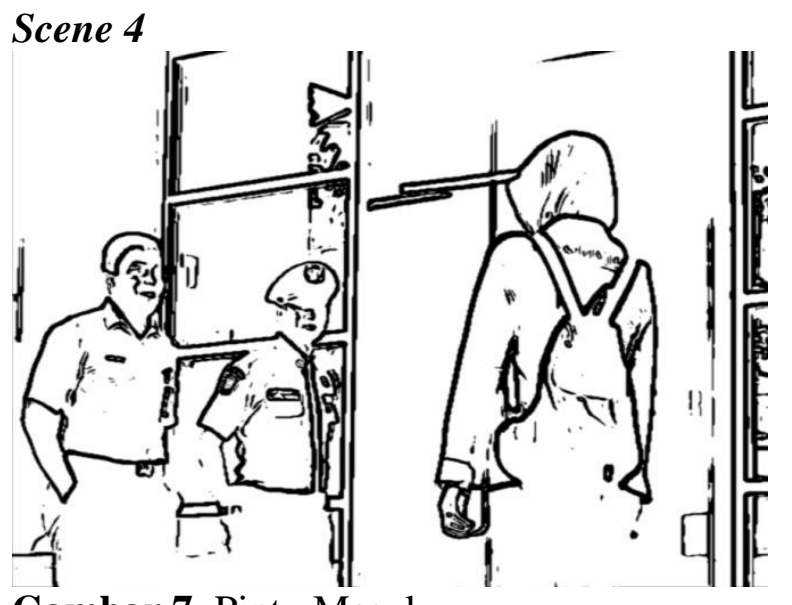

EXT / Pintu Masuk (Medium Shoot)

Gambar 7. Pintu Masuk

\section{Scane 5}

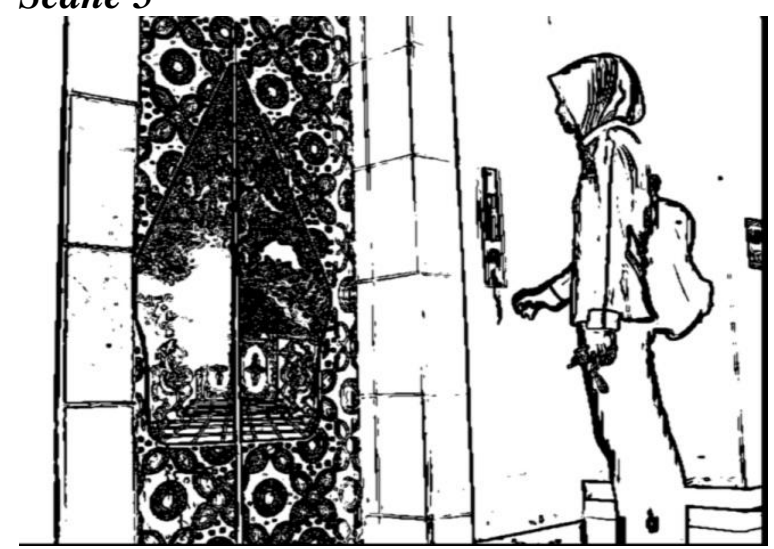

INT/ Life (Medium Shoot)

Gambar 8. Life

\section{Scane 6}

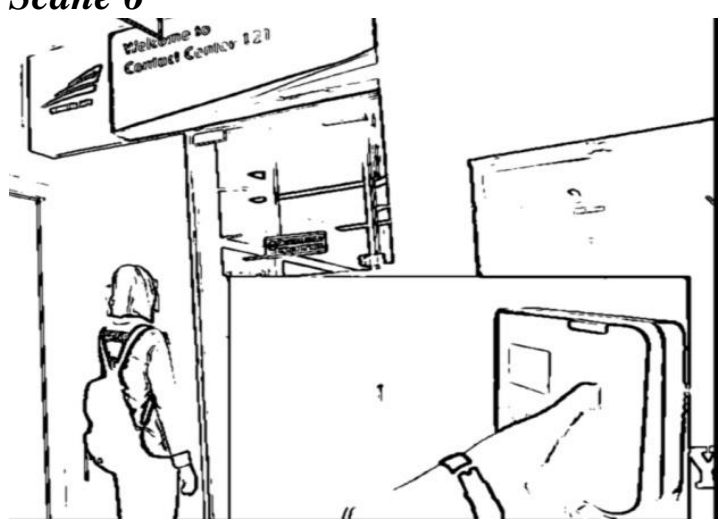

Gambar 9. Absen 


\section{Scane 7}

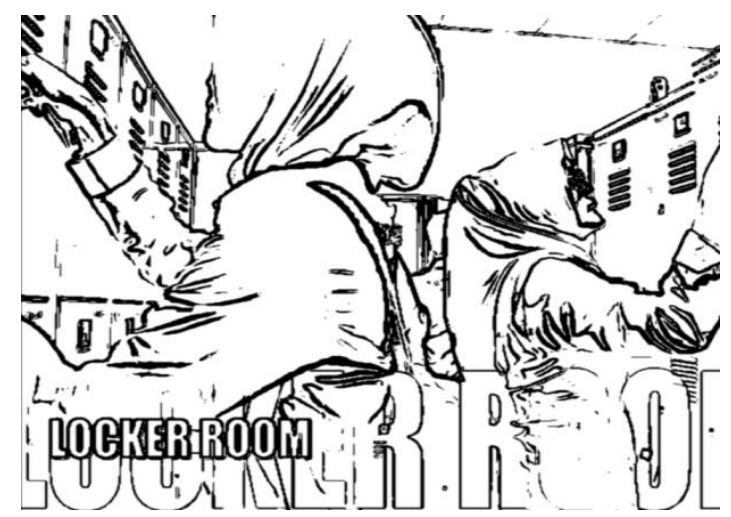

INT/ Menampilkan Video Suasana

Locker Room (medium shoot)

Gambar 10. Menampilkan Video Suasana Locker Room

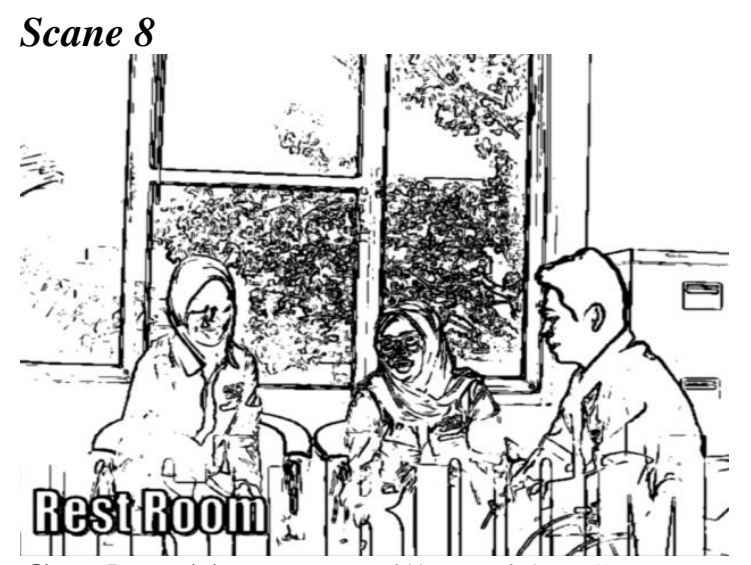

INT / Menampilkan video Suasana

Rest Room (Medium Ful Shoot)

Gambar 11. Menampilkan video Suasana Rest Room

\section{Adobe Premier CS3}

program yang dibuat untuk editing video dan bagian dari Adobe Creative Suite, rangkaian desain grafis, editing video, dan pengembangan aplikasi web yang dibuat oleh Adobe Systems.

\section{Corel Video Studio X5}

Alat yang ampuh, efektif dan mudah bekerja dengan cepat melakukan siklus lengkap dari pengolahan video dari menangkap untuk ditampilkan.

\section{Adobe Photoshop CS3}

Perangkat lunak ini banyak digunakan oleh fotograferdigital dan perusahaan iklan sehingga dianggap sebagai pemimpin pasar (market leader) untuk perangkat lunak pengolah gambar/foto, dan, bersama Adobe Acrobat, dianggap sebagai produk terbaik yang pernah diproduksi oleh Adobe Systems.

\section{LITERATURE REVIEW}

1. "Perancangan Video Profile Sebagai Penunjang Media Informasi Dan Promosi Pada Sma Citra Islami". Penelitin ini mengenai pembuatan media video profile untuk meningkatkan minat calon pendaftar untuk bergabung di lembaga tersebut. SMA Citra Islami Tangerang saat ini belum mempunyai sebuah video profile, yang dimana lembaga sekolah tersebut perlu adanya media video profile yang menarik dan dapat menjadi media informasi dan media promosi khususnya bagi calon para siswa dan siswi baru. 
2. "Pembuatan Video Company Profile Pada SMA Muhammadiyah 1 Karanganyar". Pelitian ini mengenai bagaimana menciptakan sebuah media promosi yang menarik dan efektif. Penulis yang akan membuat penelitian di lembaga tersebut akan merancang media promosi universitas widyagama malang dengan konsep animasi 2 dimensi.

3. Pembuatan Video Company Profile Pada Sekolah Menengah Atas Muhammadiyah 1 Karanganyar". Penelitian ini mengenai tujuan yang ingin di capai si penulis adalah untuk menghasilkan video profil Muhammadiyah 1 Karanganyar yang berbasis multimedia sebagai media promosi dan dokumentasi. Manfaat penelitian ini adalah sebagai dokumentasi serta media promosi dan informasi tentang lembaga pendidikan tersebut.

4. "Pembuatan Video Profil Sekolah Menengah Kejuruan Negeri 1 Gondang". Pelitian ini mengenai Sekolah Menengah Kejuruan Negeri 1 Gondang ini belum mempunyai sarana untuk mempromosikan sekolah kepada masyarakat. Manfaat penelitian ini adalah sebagai dokumentasi serta media promosi dan informasi tentang lembaga pendidikan tersebut.

5. "Pembuatan Video Profil Sekolah Menengah Pertama Negeri Dua Sambungmacan Sragen Menggunakan Komputer Multimedia". Penelitian ini mengenai merancang media audio visual agar dapat menjadi daya tarik yang efektif, terutama dalam penyampaian promosi dan informasi. SMA Negeri 15 Kota Tangerang merupakan salah satu lembaga pendidikan di Kota Tangerang dan mempunyai permasalahan adalah bentuk promosi yang digunakan masih berupa media komunikasi visual, seperti pamphlet, spanduk, brosur, dan lainnya, sehingga sekolah tersebut membutuhkan media penunjang informasi dan promosi yang lebih menarik dan efektif yaitu dalam bentuk video profile.

\section{KESIMPULAN}

Agar perancangan video profile dan informasi lebih efektif yaitu dengan menampilkan sebuah video profile yang berisikan informasi yang berupa penjelasan detail isi video kualitasnya. Tahapan KPM yaitu preproduction, production dan postproduction, agar mudah dalm membuat suatu projek perlu menyatukan berbagai animasi, gambar, dan audio visual yang dikemas kedalam video profile, dan video ini ditampilkan dalam durasi yang tidak terlalu panjang namun jelas, agar lebih efektif dan tepat sasaran video ini di implementasikan melalui DVD, Youtube dan website supermal karawaci.

\section{DAFTAR PUSTAKA}

[1]. Abdulhak, Ishak. Doni Darmawan. 2013. “ Teknologi Pendidikan .” PT Remaja Rosdakarya : Bandung.

[2]. Abdillah, Fadhly. Dhamar Adhiguna, Agus Sevtiana. 2017. “Perancangan Video Profile Sebagai Media Promosi STMIK CIC Dengan Tehnik Motion Graphic Menggunkan Perangkat Lunak Komputer Graphic ."JURNAL DIGIT Vol. 7, No. 1. STMIK CIC Cirebon.

[3]. Abidin. Elfira Rosana. Sukirman Rahim, Meylan Saleh. 2015. “ Kemampuan Guru Dalam Mengolah Media Pembelajaran Pada Mata Pelajaran IPA di SDN No. 104 Kota Utara Gorontalo, "Karya Ilmiah Mahasiswa Fakultas Ilmu Pendidikan Vol. 3 No. 3.Gorontalo.

[4]. Adebowale, Aina, J. and Adekanye E. Ademola. 2013. “ Audio-Visual Resources Availability And Use For Library Services Among Colleges Of Education In Lagos State Nigeria .”Journal IJLIS-International Journal of Library and Information Science Vol. 5, No. 10.Lagos State University . Ojo Lagos Nigeria. 
[5]. Andreanus, Jansen. 2015. “Tindak Ujar Ekspresif Dalam Film Freedom Writer, "Fakultas Ilmu Budaya Manado, Sulawesi Selatan.

[6]. Anggraini, Amelia. 2014. “Pengaruh Produk Positiyoning Terhadap Loyalitas Audience Pada Radio Mentari 95.10 Fm Pekan Baru, "Sripsi Thesis, Universitas Negeri Sultan Syarif Kasim Riau,Riau.

[7]. Anggraini, Lia, S.Kirana Nathalia. 2014. “ Desain Komunikasi Visual . Nuansa Cendikia : Bandung.

[8]. Anita, Diajeng, Ria. Fitri Marisa. 2017. “Rancangan Video Media Promosi Berbasis Motion Graphic 2D Untuk Meningkatkan Jumlah Mahasiswa Universitas Widyagama Malang," Journal of Information Technology and Computer Sciene (JOINTECS) Vol. 1, No. 2. Universitas Widyagama Malang, Jawa Timur.

[9]. Aris.Indra Budi Saputra, Kevin Macario, Adam Maulana, Faisal Mustaqim. 2015. “ Perancangan Media Company Profile Sebagai Penunjang Promosi dan Informasi Pada PT. Pos Indonesia (PERSERO) Tangerang 15000 .” Seminar Nasional Teknologi Informasidan Multimedia, STMIK AMIKOM Yogyakarta, Jawa Tengah.

[10]. Aveyard, Helen. 2014. "Doing A Literature Review In Helath And Social Care A Partical Guide $3^{\text {rd }}$ Edition."McGraw-Hill Education, New York. 